With regard to prevention of pressure sores-this was the other reason why this bed had been designed. They had not had a single pressure sore by turning the patient from side to side. This was just a confirmation of his views, held since 1944, that in the acute cases there was no need to put the patient in prone position to prevent sores but if one could relieve pressure from sacrum, hips, ankles and heels by regular turning day and night from the supine to the lateral position, no pressure sores would develop.

With regard to the question whether one could operate on this bed-he thought one could operate, as far as applying the traction. As a matter of fact, in one of his first cases in 1944 with a complete lesion at C6, he did the caliper traction in the ward on an ordinary hospital bed because the patient was so ill. One could use any bed, if necessary, in a case of emergency.

It is true that the tilting and turning bed was wider than the ordinary tilting bed, but it was designed for the comfort of acute patients, in particular those who had high lesions and those who were admitted with associated injuries. They admitted to Stoke Mandeville patients who had not only a severe fracture dislocation of the spine but associated injuries to the chest, ribs and scapula. They had at present a girl who had both scapulae broken. He did not need to say how difficult it was to turn such a patient manually by the staff, in particular at night. However, it might be possible to diminish the width of the bed in due course.

A very important point was the great difficulty every hospital in every country had today with staff, in particular at night time, and it was indeed a very great advantage just to turn the patient in such a bed, by pressing a button, whether he were paralysed or had had a brain operation or whether he were seriously ill from any other affliction.

\title{
DEMONSTRATION OF A SPECIAL ELECTRIC CONTROL FOR A POWER-DRIVEN WHEELCHAIR FOR HIGH SPINAL CORD LESIONS
}

\author{
By L. Guttmann and R. G. Maling \\ National Spinal Injuries Centre, Stoke Mandeville Hospital, Aylesbury, England
}

AN electric control for a power-driven wheelchair designed at the Electro-Mechanical Laboratory of the National Spinal Injuries Centre is demonstrated, whereby a patient with a very high cervical lesion can be made more independent. The young lady was admitted with a complete tetraplegia below $\mathrm{C}_{4}$. She was critically ill, had to have a tracheostomy done quickly, but fortunately she recovered to a certain extent as she has now some function of deltoid and biceps but no finger movements whatsoever. One does not need to stress how difficult it is to make patients with these high cervical lesions relatively independent. We have devised a gadget by which the patient with her left arm can control the chair quite easily.

The disadvantage for this level of lesion with the conventional power-drive chair is first of all that the joy-stick is operating against four micro-switches and, therefore, one has only on/off control. The speed is usually switched by two quite stiff toggle switches, both of which have to be moved to get one through four speed ranges. So, first of all the jerkiness caused by the simple micro-switches meant that above speed 2 the acceleration imparted by the motors threw the arm backward so there was then a tendency for the motor to switch on and off rapidly and the arm would go into oscillation. Therefore, we devised a system whereby the same joystick now controls two potentiometers, and these go to a transistorised device 
which gives proportional speed control. This means that when the arm pushes the joy-stick forward it starts at a speed slightly below the bottom previously switchcontrol speed. This means that there is no tendency for the arm to be thrown into oscillation. Further movement of the arm forward progresses through to the full former speed obtained by the ordinary switches. The voltage drop by this system does not adversely affect top speed of the system.

Now we have proportional control over speed, and by pushing the joy-stick sideways the proportional characteristic also applies to the steering, so both speed and steering are now smooth.

\title{
ELECTRICAL STIMULATION OF THE BLADDER IN CLINICAL PRACTICE
}

\author{
Professor R. Ascoli \\ Servicio Urologico dell' Ospedele C.T.R. dell' I.N.A.I.L., Milan, Italy
}

THE author studied a device, to be applied in the clinical field, which might elicit contraction of the vesical muscles by electrical stimulation. After many experiments he concluded that the most suitable current is the galvanic current of 5-millisecond-rectangular impulse, 20-50-frequency every second, and a 20-80milliamperes intensity. The device for direct application to the bladder consists of an electrode-catheter, lightly curved at the end, insulated on all sides except at the point which hooks the vesical neck; the second electrode consists of an usual electrocoagulation electrode which runs inside the electrode-catheter, leaves the latter near its inner end and is in contact with the posterior wall of the bladder. The inner part of the device is in contact with the Lewis' cystometer which records the increase of the vesical pressure. Such a device is able to elicit contraction of the vesical muscular system. Technique and results are described.

\section{Discussion}

Harris, $P$., wondered why the speaker apparently had dismissed altogether this idea of implanted electrical stimulators controlled by radio-frequency transmitter unit. This was in the early stage; they had been experimenting in Edinburgh for some little time and a dog was a very good subject for experiment. He thought that these stimulators would be further sophisticated and developed in the hope that they could be used at a very early stage after spinal injury.

Ascoli, R., said he was quite aware of the possibility here and had studied the methods of the Americans but these were very traumatic surgical procedures. It was necessary to perform a laparatomy and implant on the bladder wall an instrument which was quite heavy and space-taking. On several occasions it had been necessary to re-operate because of defective instrumentation within the abdomen and most of the experiments up till now had been conducted on animals and very few on humans.

Rossier, A. (Switzerland), said he would like to ask Professor Ascoli the following. question: He had said that he had observed during stimulation contraction of abdominal muscles and muscles of the thigh, and he had suggested that this could be useful. He would like to ask whether Professor Ascoli was sure that this was useful and not damaging, because of the following fact. If one had contraction of the striated muscles of the pelvic 